\title{
HIGH EFFICIENCY GENERATION OF HYDROGEN FUELS USING NUCLEAR POWER
}

\author{
for the period \\ August 1, 1999 through October 31, 1999
}

by

L.C. BROWN

Prepared under

Nuclear Energy Research Initiative (NERI)

Program. DE-FG03-99SF21888

for the U.S. Department of Energy

GENERAL ATOMICS PROJECT 30047

DATE PUBLISHED: JANUARY 2000 


\section{DISCLAIMER}

This report was prepared as an account of work sponsored by an agency of the United States Government. Neither the United States Government nor any agency thereof, nor any of their employees, make any warranty, express or implied, or assumes any legal liability or responsibility for the accuracy, completeness, or usefulness of any information, apparatus, product, or process disclosed, or represents that its use would not infringe privately owned rights. Reference herein to any specific commercial product, process, or service by trade name, trademark, manufacturer, or otherwise does not necessarily constitute or imply its endorsement, recommendation, or favoring by the United States Government or any agency thereof. The views and opinions of authors expressed herein do not necessarily state or reflect those of the United States Government or any agency thereof. 


\section{DISCLAIMER}

Portions of this document may be illegible in electronic image products. Images are produced from the best available original document. 


\title{
High Efficiency Generation of Hydrogen Fuels Using Nuclear Power
}

\author{
Nuclear Energy Research Initiative (NERI) \\ Program DE-FG03-99SF21888 \\ Technical Progress Report \\ August through October 1999
}

Highlights

- The methodologies for searching the literature for potentially attractive thermochemical water-splitting cycles, storing cycle and reference data, and screening the cycles have been established.

- The water-splitting cycle screening criteria were established on schedule.

\section{Introduction}

Future nuclear reactors will operate at higher efficiencies and therefore at higher temperature than current reactors. High temperatures present the potential for generating hydrogen at higher efficiencies than can be realized via conventional electrolysis. Thermochemical processes for the generation of hydrogen from water were extensively studied in the 70 s and early $80 \mathrm{~s}$ both in the U.S. and abroad, however thermochemical water-splitting has not been pursued in the U.S. at any significant level since that time. In Phase 1 we are reviewing this early work and subsequent work to determine the process best suited to hydrogen production from the advanced nuclear reactors expected to be available in the next 20 to 30 years. Our first major task is to review the available literature on thermochemical water-splitting and select approximately twenty processes worthy of detailed analysis. Figure 1 shows a flow diagram of the decision processes used for this effort.

\section{Project Coordination}

The project is a cooperative endeavor of the three participants: General Atomics (GA), Sandia National Laboratories (SNL) and the University of Kentucky (UK). Table 1 indicates the tasks to be performed and the status of each task. Each organization participates, to some extent in every task but the lead organization is indicated on the task schedule, Fig. 2. The spending profiles for all three organizations are given in Fig. 3. All tasks are on schedule but costs for the quarter were less than expected. Less effort was required by GA and SNL to establish the screening criteria.

\section{Literature Survey}

The literature survey is the primary responsibility of the UK with the support of GA and SNL. The initial tasks were to determine the search criteria and select the literature databases to be searched. Other parallel tasks were to select a database program with which to manipulate the search results and to devise a structure for the project database. A database structure is required which will support the manipulations required to evaluate each cycle according to the preliminary screening criteria. 
The project database was developed at SNL with consultation from the other participants. A relational database was implemented in Microsoft Access with the structure indicated in Fig. 4. This database format makes it easy to search for commonality between various cycles. The structure is designed to help eliminate duplicate entries of water-splitting cycle and literature sources.

Keywords were chosen for the literature search and test searches were made using free or inexpensive databases as a means of testing search strategies. Thermochemical generation of hydrogen is usually referred to, by those who practice the art, as watersplitting. It was quickly determined that searches based upon water-splitting and "watersplitting" lead to many thousands of hits - few of which were pertinent to the desired subject. Inspection of the titles showed a predominance of biological, biochemical and photochemical articles and numerous titles dealing with corrosion and radiolysis, moreover, some authors do not use the term water-splitting. Attempts to limit the search, by exclusion of biological and photochemical terms (Boolean NOT) exceeded the capabilities of the search engines before a significant reduction in number of hits was realized. It has proven to be much more profitable to build up a search criteria using inclusive criteria (Boolean AND/OR). The primary limit on the search has been the requirement of the inclusion of the term "thermochemical".

Chemical Abstracts Service of the American Chemical Society provides convenient access to many databases. Searching a large number of different databases can be very expensive and may produce a large number of redundant references to a single publication. The web site stnweb.cas.org allows one to simultaneously search a large number of databases at no cost but the only results provided are the number of hits. This free search does allow one to quickly and inexpensively test various search strategies. Various Boolean searches were made of the CHEMENG Cluster of databases in an attempt to optimize the search string and select the databases to be used for the "real" search. The search term [(water-splitting or water-splitting or ((hydrogen or h2) and (production or generation))) and thermochemical] appeared to give very good results. The results from the databases showing a significant number of hits are given in Table 2.

The CAPLUS database was subjected to a full data retrieval search: preliminary indications are that over $50 \%$ of the hits are for papers discussing thermochemical watersplitting. From the descriptors given for the various databases, it is likely that most of the other databases, with the possible exception of NTIS, will either duplicate the results from CAPLUS or be off-topic. The data from the CAPLUS search is being screened for relevance before entry into the project database. We will verify that the search of CAPLUS has found most (if not all) pertinent cycles by spot comparison with the results from searching the other literature databases.

Many cycles are the subject of previous review articles. Data entry into the project database is well underway for these cycles. As data from the literature search is added to the project database, it will be linked appropriately. If the cycle, which is the subject of the publication, exists in the database, the publication data will be simply linked to the cycle data. If the cycle is new, both the cycle and publication data will be entered. The cycle will then be available for linking if other publications are found which refer to the cycle. 


\section{Screening Criteria}

Screening criteria were developed, under the direction of GA, as a means of winnowing the numerous proposed water-splitting cycles down to a manageable twenty or so. The criteria were scheduled to be completed on October $1^{\text {st }}$ and formal ratification of the criteria was accomplished on that date. The criteria were chosen to emphasize those water-splitting cycles best suited to a high efficiency nuclear reactor. Table 3 indicates the basis for each criterion and the measure chosen by which to evaluate the cycle according to the criteria. Table 4 indicates the scales by which each measure will be converted into a score. Each water-splitting cycle will be scored according to each criterion on a scale from zero to ten. Originally, it was thought that the each criterion would need to be individually weighted to arrive at a final score for a cycle. That did not prove to be the case and it was decided to weigh all criteria equally. The total score over all criteria for each cycle will be used to rank the cycles and eliminate all but the top twenty.

\section{Scheduled Progress}

All tasks are proceeding on schedule. The one task scheduled for completion in this time frame, preparation of the screening criteria, was completed on time.

\section{Next Quarters Work}

Ranking of the cycles according to the screening criteria is scheduled to begin in early December. Both the literature survey and the screening are scheduled to continue throughout the next quarter. 


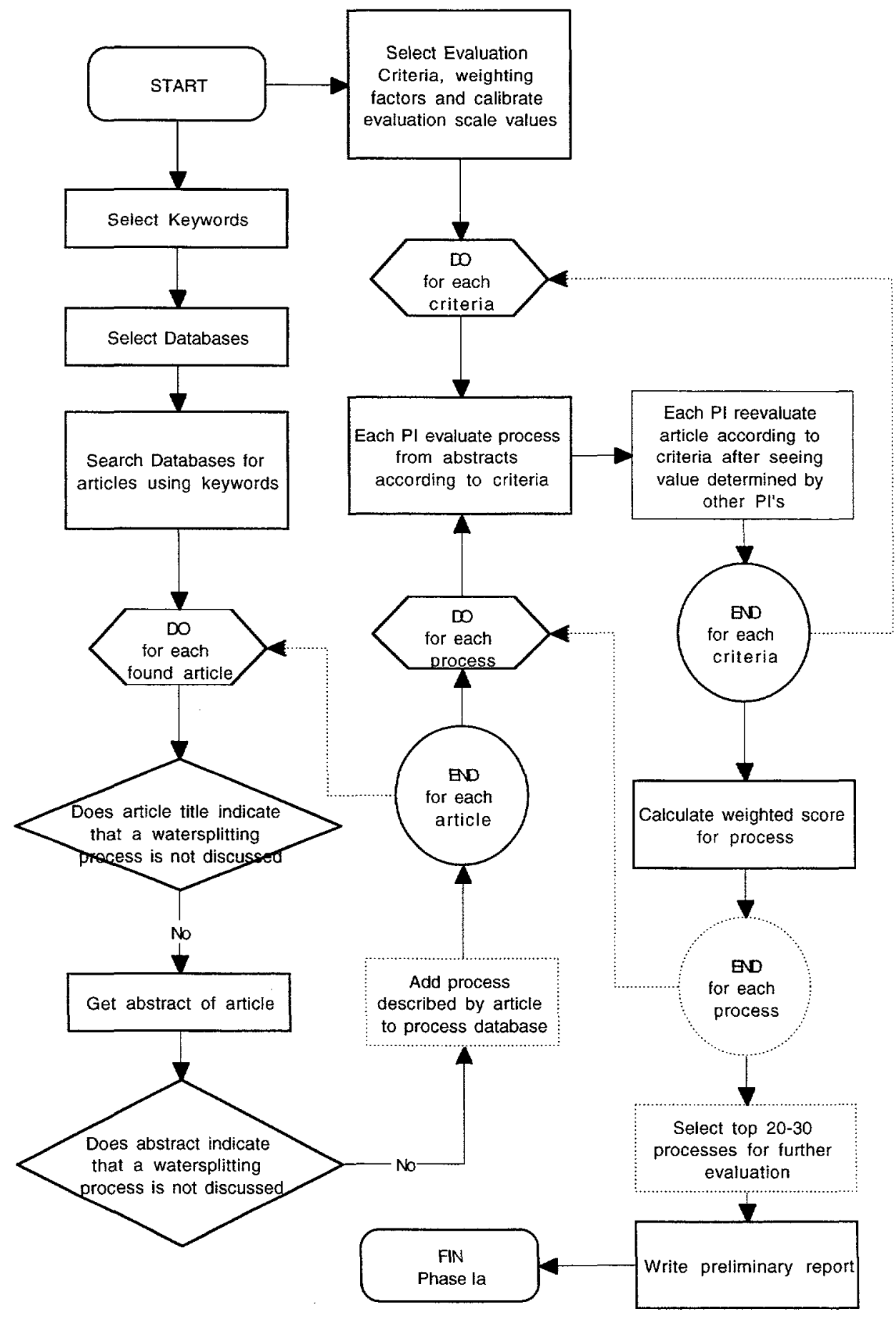

TNote: weighting factors of one were chosen for all criteria.

Fig. 1. Flow Diagram of Literature Survey and Screening Procedure 
Table 1. Summary of NERI Tasks - Phases 1-3

\begin{tabular}{|c|c|c|c|c|}
\hline $\begin{array}{l}\text { Identification } \\
\text { Number }\end{array}$ & $\begin{array}{c}\text { Milestone/ } \\
\text { Task Description }\end{array}$ & $\begin{array}{c}\text { Planned } \\
\text { Completion } \\
\text { Date }\end{array}$ & $\begin{array}{l}\text { Actual } \\
\text { Completion } \\
\text { Date }\end{array}$ & Comments \\
\hline 1.1 & Literature survey of new processes & Fri $2 / 25 / 00$ & & Work in progress and on schedule \\
\hline 1.2 & Develop screening criteria & Fri 10/1/99 & Fri $10 / 1 / 98$ & Completed on schedule \\
\hline 1.3 & Carry out first round screening & Fri $3 / 10 / 00$ & & Work not begun \\
\hline 1.4 & Short report on conclusions & Fri $3 / 31 / 00$ & & Work not begun \\
\hline 1.5 & Carry Out Second Round Screening & Fri $6 / 2100$ & & Work not begun \\
\hline 1.6 & Write Phase 1 report & Fri $6 / 30 / 00$ & & Work not begun \\
\hline 2.1 & $\begin{array}{l}\text { Carry out detailed evaluation of few } \\
\text { processes to select one }\end{array}$ & Fri $9 / 29 / 00$ & & Phase 2 \\
\hline 2.2 & Define reactor thermal interface & Fri $9 / 29 / 00$ & & Phase 2 \\
\hline 2.3 & $\begin{array}{l}\text { Preliminary engineering design of } \\
\text { selected process }\end{array}$ & Wed 11/22/00 & & Phase 2 \\
\hline 2.4 & Develop flowsheet & Fri $4 / 20 / 01$ & & Phase 2 \\
\hline 2.5 & Conceptual equipment specifications & Fri $5 / 4 / 01$ & & Phase 2 \\
\hline 2.6 & Write Phase 2 Report & Fri $6 / 30 / 01$ & & Phase 2 \\
\hline 3.1 & $\begin{array}{l}\text { Develop concepts for auxiliary } \\
\text { systems }\end{array}$ & Fri $10 / 26 / 01$ & & OPhase 3 \\
\hline 3.2 & Refine flowsheet & Fri $1 / 11 / 02$ & & Phase 3 \\
\hline 3.3 & Size/cost process equipment & Fri 3/22/02 & & Phase 3 \\
\hline 3.4 & Evaluate process status & Fri $5 / 3 / 02$ & & Phase 3 \\
\hline 3.5 & Write Final Report & Fri $6 / 28 / 02$ & & Phase 3 \\
\hline
\end{tabular}




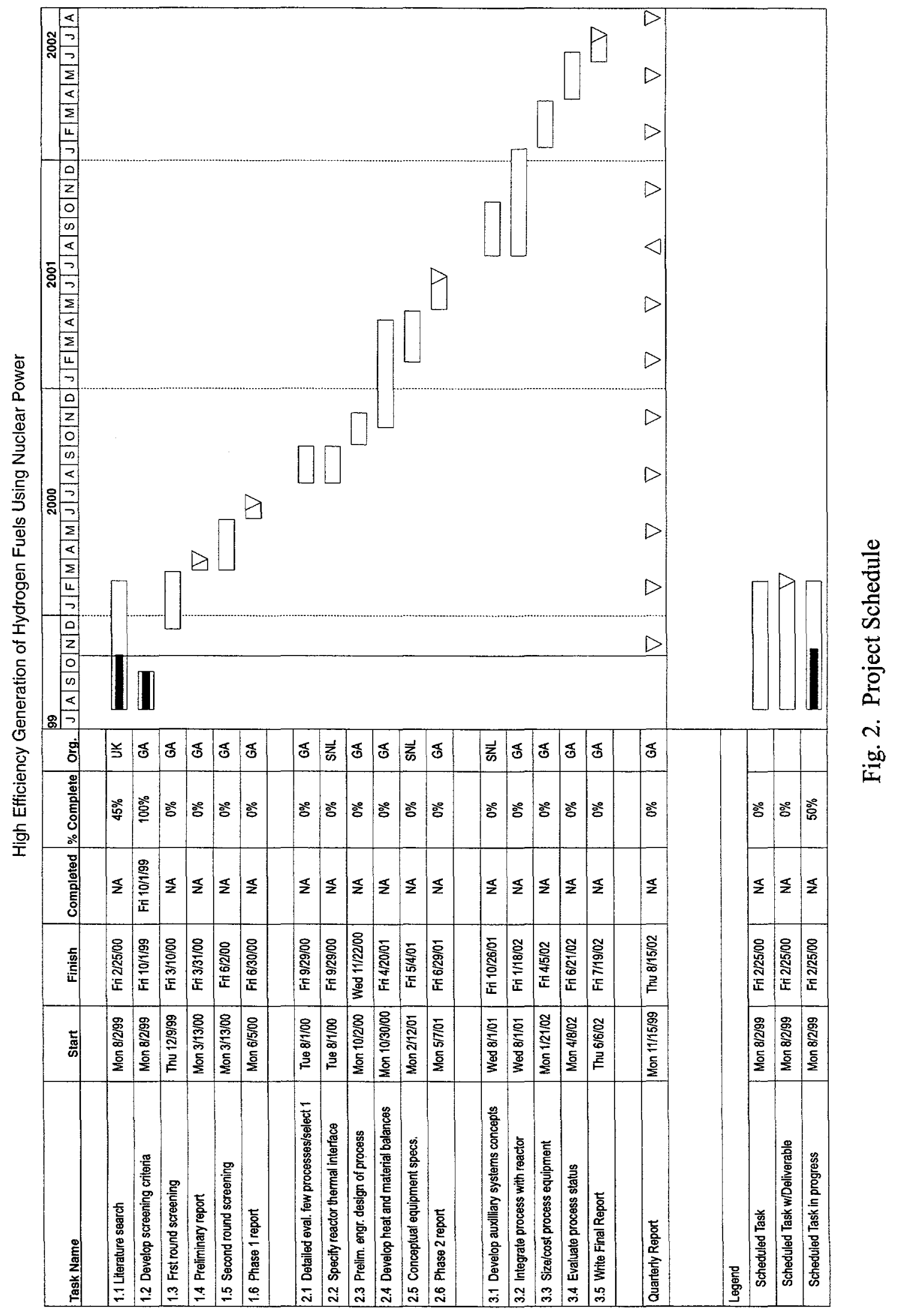




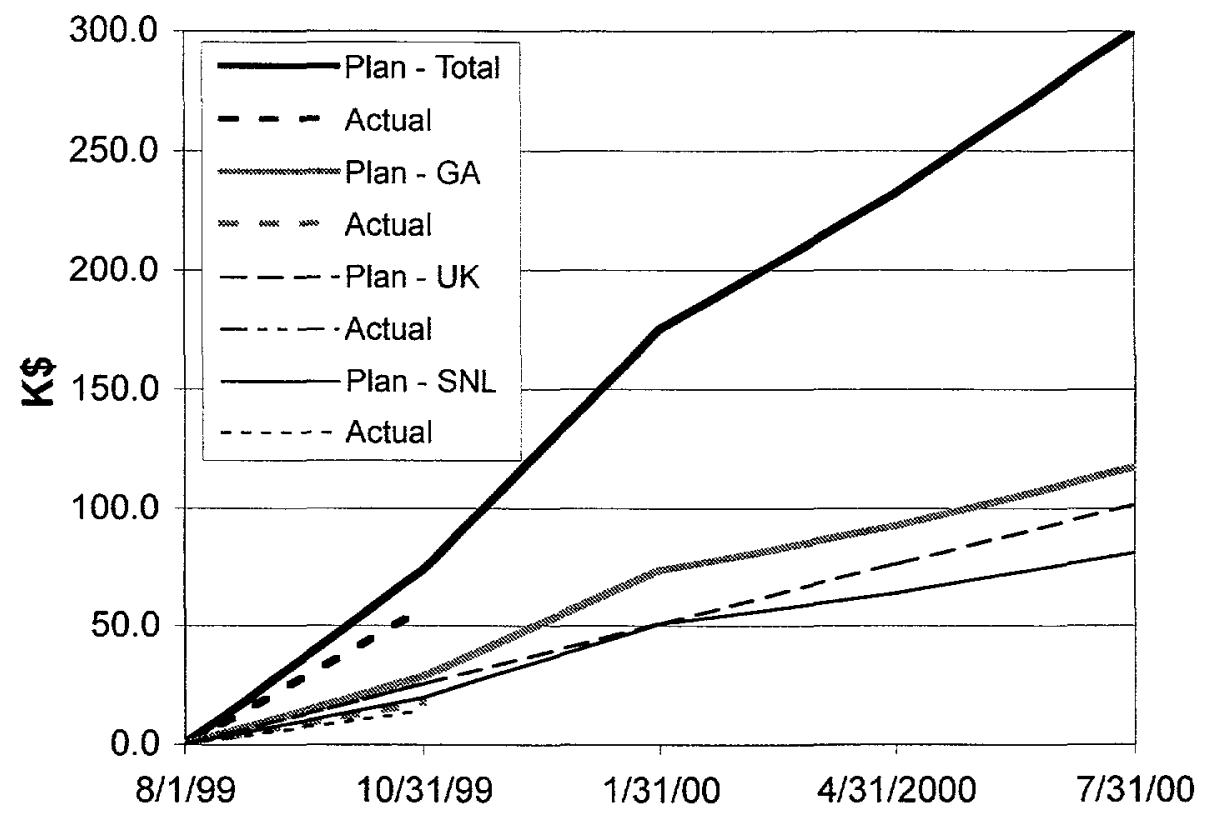

Fig. 3. Spending Profile. 


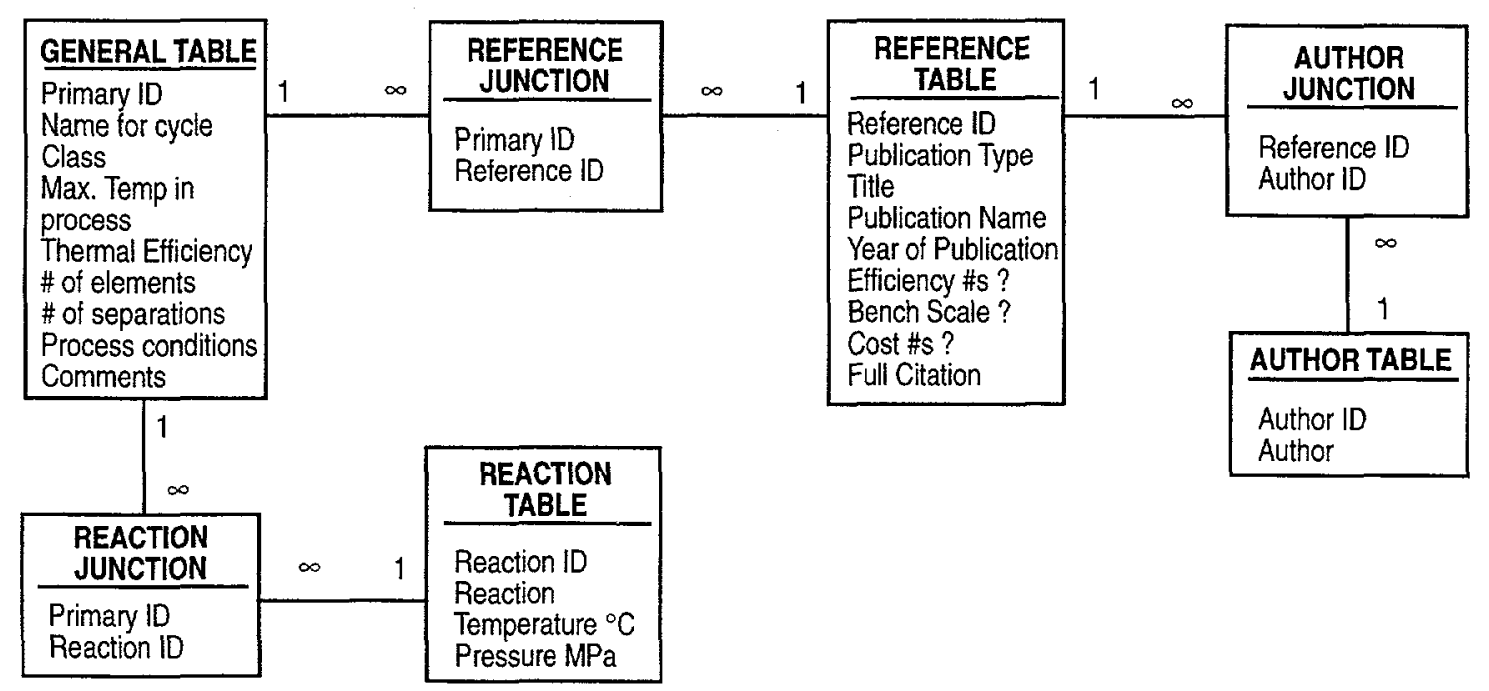

Fig. 4. Project Database Structure

Table 2. Database Search Results

Hits Databases Description

905 CAPLUS Chemical Abstracts Plus

448 COMPENDEX COMPuterized ENgineering InDEX

440 NTIS National Technical Information Service

322 INSPEC The Database for Physics, Electronics and Computing. INSPEC corresponds to Physics Abstracts, Electrical \& Electronics Abstracts, Computer \& Control Abstracts, and Business Automation.

232 SCISEARCH Science Citation Index Expanded

68 CEABA Chemical Engineering And Biotechnology Abstracts

33 PROMT Predicasts Overview of Markets and Technology - abstracts trade and business journals

28 INSPHYS INSPHYS is a supplementary file to the INSPEC database. It contains those records from the former PHYS File from 1979 through 1994 that do not appear in INSPEC 
Table 3. Screening criteria

\begin{tabular}{|c|c|c|c|}
\hline \multicolumn{4}{|c|}{ Initial Screening Criteria } \\
\hline & Desirable Characteristic & Rational & Measure \\
\hline 1 & $\begin{array}{l}\text { Higher ranked cycles will have a minimum number of } \\
\text { chemical reactions steps in the cycle. }\end{array}$ & $\begin{array}{l}\text { A smaller number of chemical reactions indicates a simpler } \\
\text { process and lower costs. }\end{array}$ & Score is based on number of chemical reactions. \\
\hline 2 & $\begin{array}{l}\text { Higher ranked cycles will have a minimum number of } \\
\text { separation steps in the cycle. }\end{array}$ & $\begin{array}{l}\text { A smaller number of chemical separations indicates a simpler } \\
\text { process and lower costs. }\end{array}$ & $\begin{array}{l}\text { Score is based on number of chemical separations, excluding } \\
\text { simple phase separation. }\end{array}$ \\
\hline 3 & $\begin{array}{l}\text { Higher ranked cycles will have a minimum number of } \\
\text { elements in the cycle. }\end{array}$ & $\begin{array}{l}\text { A smaller number of chemical elements indicates a simpler } \\
\text { process and lower costs. }\end{array}$ & $\begin{array}{l}\text { Score is based on number of elements, excluding oxygen and } \\
\text { hydrogen }\end{array}$ \\
\hline 4 & $\begin{array}{l}\text { Higher ranked cycles will employ elements which are } \\
\text { abundant in the earth's crust, oceans and atmosphere and } \\
\text { which are easily separated from other elements. }\end{array}$ & $\begin{array}{l}\text { Use of abundant elements will lower the cost and permit the } \\
\text { chosen technology to be implemented on a large scale. There } \\
\text { may be strategic availability issues. }\end{array}$ & Score is based on least abundant element in cycle. \\
\hline 5 & $\begin{array}{l}\text { Higher ranked cycles will minimize the use of expensive } \\
\text { materials of construction by avoiding corrosive chemical } \\
\text { systems, particularly in heat exchangers. }\end{array}$ & $\begin{array}{l}\text { Improved materials of construction may allow consideration of } \\
\text { processes previously dismissed yet the effect of materials cost } \\
\text { on hydrogen production efficiency and cost must be considered. }\end{array}$ & $\begin{array}{l}\text { Score is based on the relative corrosiveness of the process } \\
\text { solutions. }\end{array}$ \\
\hline 6 & Higher ranked cycles will minimize the flow of solids. & $\begin{array}{l}\text { Chemical plant costs are considerably higher for solids } \\
\text { processing plants. Flow of solid materials also corresponds to } \\
\text { increased maintenance costs due to wear and to increased } \\
\text { downtime due to pluggage and unscheduled equipment failure. }\end{array}$ & Score is based on minimization of solid fow problems. \\
\hline 7 & $\begin{array}{l}\text { Higher ranked cycles will have maximum heat input } \\
\text { temperature compatible with high temperature heat transfer } \\
\text { materials. }\end{array}$ & $\begin{array}{l}\text { High thermal efficiency cannot be realized without a high } \\
\text { temperature heat input to the watersplitting process. The limit on } \\
\text { temperature will be the thermal and mechanical performance of } \\
\text { the heat transfer material separating the reactor coolant from the } \\
\text { process stream requiring the highest temperature. }\end{array}$ & $\begin{array}{l}\text { Score is based on the high temperature heat input to the process } \\
\text { being close to that delivered by an advanced nuclear reactor. }\end{array}$ \\
\hline 8 & $\begin{array}{l}\text { Higher ranked cycles will have been the subject of many } \\
\text { papers from many authors and institutions. }\end{array}$ & $\begin{array}{l}\text { Cycles that have been thoroughly studied in the literature have a } \\
\text { lower probability of having undiagnosed flaws. }\end{array}$ & $\begin{array}{l}\text { Score will be based on the number of papers published dealing } \\
\text { with the cycle. }\end{array}$ \\
\hline & $\begin{array}{l}\text { Higher ranked cycles will have been tested at a moderate or } \\
\text { large scale, }\end{array}$ & $\begin{array}{l}\text { Relatively mature processes will have had their unit operations } \\
\text { tested at relatively large scale. Processes for which the basic } \\
\text { chemistry has not been verified are suspect. }\end{array}$ & $\begin{array}{l}\text { Score will be based on the degree to which the chemistry of the } \\
\text { cycle has been actually demonstrated and not just postulated. }\end{array}$ \\
\hline & $\begin{array}{l}\text { Higher ranked cycles will have good efficiency and cost data } \\
\text { available. }\end{array}$ & $\begin{array}{l}\text { A significant amount of engineering design work is necessary to } \\
\text { estimate process efficiencies and production costs. Note: cost } \\
\text { estimates in the absence of efficiency calculations are } \\
\text { meaningless and will not be considered. }\end{array}$ & $\begin{array}{l}\text { Score will be based on the degree to which efficiencies and cost } \\
\text { have been estimated. }\end{array}$ \\
\hline
\end{tabular}


Table 4. Scale for scoring each cycle according to the measure for each criterion

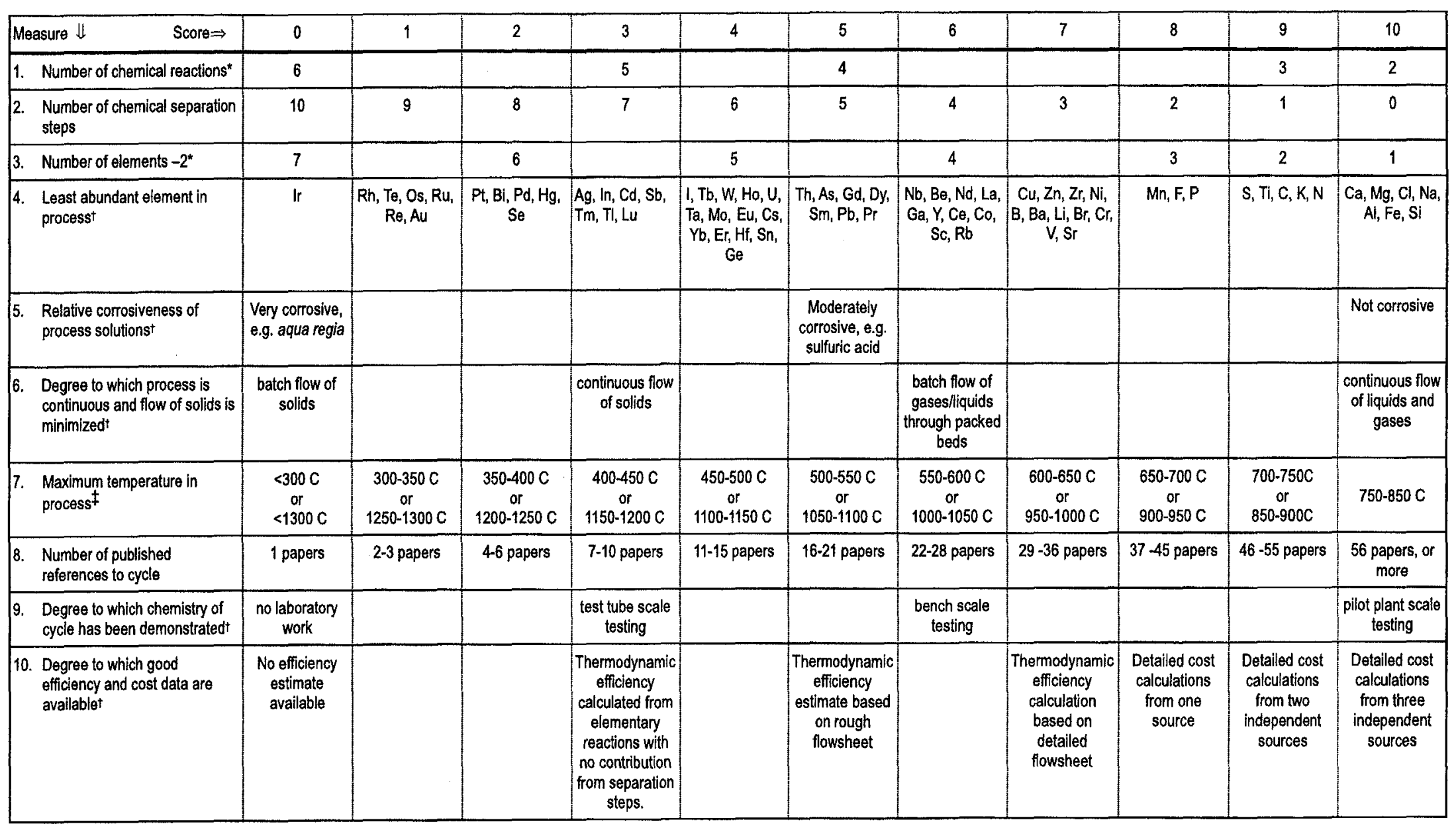

\footnotetext{
All possible scores are not possible for integer some integer criteria

$\dagger \quad$ Interpolate scores between defined scale points

\$ Temperature either higher or lower than optimum will lead to reduced score

Note: All criteria receive equal weighting.
} 